\title{
DIAGNÓSTICO ARBÓREO COMPARATIVO EM BAIRROS DE LENÇÓIS PAULISTA - SP
}

\author{
COMPARATIVE ARBOREAL DIAGNOSIS IN LENÇÓIS PAULISTA - SP DISTRICTS
}

Mateus de Souza Rolon ${ }^{1}$, Marcos Vinicius Bohrer Monteiro Siqueira ${ }^{2}$

\section{RESUMO}

Devido ao crescimento desordenado e acelerado nas áreas urbanas, houve a necessidade da utilização de áreas verdes com o intuito de harmonizar o desenvolvimento das cidades e manter a qualidade de vida dos habitantes. $O$ presente trabalho teve como objetivo caracterizar qualitativamente e quantitativamente a arborização dos bairros Jardim Granville, Jardim Ibaté e Jardim Ubirama, localizados em Lençóis Paulista - SP. Foi realizado um levantamento do número de indivíduos e sua taxonomia. O estudo diagnosticou as árvores mais utilizadas na arborização urbana dos bairros apresentados com destaque para as espécies Lagerstroemia indica, Licania tomentosa, Paubrasilia echinata, Salix $x$ pendulina, Murraya paniculata e Woydetia bifurcata. Também foi determinado o estado geral dos indivíduos, dos quais predominou os estados de Bom e Regular. Problemas relacionados à fitossanidade como ataques de cupins e formigas aconteceram de forma mais recorrente no bairro Jardim Ibaté, com $20 \%$ de indivíduos atacados. O estudo permitiu observar a qualidade da arborização entre os bairros da cidade e apontar de forma progressiva qual bairro possui mais infraestrutura quanto a arborização.

Palavras-chave: Análise quali-quantitativa; Planejamento Urbano; Vias públicas.

\section{ABSTRACT}

Due to the disorderly and accelerated growth in urban areas, it was necessary to use green areas in order to harmonize the development of cities and maintain the quality of life of the inhabitants. The present study had the objective to characterize qualitatively and quantitatively the afforestation of the Jardim Granville, Jardim Ibaté and Jardim Ubirama districts, located in Lençóis Paulista - SP. A survey was made of the number of individuals and their taxonomic characteristics, such as species, family and genus. The study diagnosed that the most used trees in the urban afforestation of the districts presented were Lagerstroemia indica, Licania tomentosa, Paubrasilia echinata, Salix x pendulina, Murraya paniculata and Woydetia bifurcata. The general condition of the individuals was also determined, of which the Good and Regular conditions predominated. Problems related to plant health such as termite and ant attacks occurred more often in Jardim Ibaté district, with $20 \%$ of individuals attacked. The study allowed us to formulate comparative parameters among the city's districts and to observe in a progressive way which districts has more infrastructure in terms of urban afforestation.

Keywords: Qualiquantitative analysis; Public roads; Urban planning.

Recebido em 09.09.2017 e aceito em 23.03.2018

1 Graduando em Arquitetura e Urbanismo. Universidade do Sagrado Coração. Bauru/SP. E-mail: mateusrollonarq@gmail.com

2 Eng. Biotecnólogo. Doutor em Ecologia Aplicada. Docente na Universidade do Sagrado Coração. Bauru/SP. E-mail: mvbsiqueira@gmail.com 


\section{INTRODUÇÃO}

A forma como diversas cidades se desenvolveram, está relacionada a um processo acelerado de urbanização que aconteceu junto ao crescimento demográfico e suas demandas, das quais as cidades não possuíam preparo para acompanhar. A falta de planejamento que ocorreu com a expansão territorial, acarretou em um contexto urbano com inúmeros problemas ambientais (MORAES; GOUDARD; OLIVEIRA, 2008).

O crescimento das cidades e o aumento no número de indústrias nas áreas urbanas fizeram com que houvesse uma grande degradação do ambiente e, aliado a isso, a preocupação de investimentos em áreas verdes urbanas. Houve a necessidade da implantação de uma forma de planejamento urbano que relacionasse as áreas verdes ao crescimento demográfico, auxiliando diretamente o bom funcionamento das cidades e garantindo dessa forma o bem-estar da população (BERTINI et al., 2016).

Considerada uma ferramenta de extrema relevância na qualidade de vida, as árvores geram conforto ambiental, uma vez que colaboram para manter energia e refrigerar o clima nas cidades, e contribuem para questões sociais, criando ambientes aprazíveis para os seres humanos (SILVA; GONZALEZ; SILVA FILHO, 2011), lidando também com aspectos econômicos, através da estética que gera influência na especulação imobiliária (SANTOS; LISBOA; CARVALHO, 2012).

Mascaró e Mascaró (2005) observam que, devido às atividades que são executadas nos centros urbanos, o uso de vegetações nesses espaços acaba sendo importante e necessário para a melhoria das cidades. Neste contexto, Bertini et al. (2016) recomendam políticas públicas específicas e a participação popular no processo de melhoria contínua para o incremento das áreas verdes públicas, sobretudo nas regiões menos favorecidas.

Dentro desse escopo, a arborização urbana pode ser caracterizada como o conjunto de terras, públicas ou privadas, dotadas de indivíduos predominantemente arbóreos e localizadas dentro da cidade. A arborização urbana pode ser igualmente identificada como um fragmento de malha arbórea natural ou cultivada, que uma cidade possui em seus espaços particulares, bem como públicos (SILVA JúNIOR; MÔNICO, 1994).

A arborização urbana passou a ser vista com caráter de política pública, tendo em vista que sua proteção tem um papel fundamental para um bom desenvolvimento na região urbana e das pessoas que ali habitam. O poder público dispõe de diversas medidas técnicas para propiciar a melhoria da qualidade de vida e a conservação ambiental, sendo que dentre essas medidas está o planejamento e a implantação da arborização urbana (BOBROWSKI, 2011). Os efeitos positivos trazidos por práticas arbóreas são notórios para a preservação do 
meio ambiente, através de uma melhoria no conforto térmico, resultando consecutivamente na qualidade do ar em vias públicas (SHAMS; GIACOMELI; SUCOMINE, 2009).

Através da prática do diagnóstico por meio de inventários quali-quantitativos da malha arbórea de um determinado local, gera-se conhecimento referente à composição da flora urbana, permite-se identificar características particulares diante do seu meio circundante e, promove-se um levantamento sucinto do total de árvores destes locais para futuros manejos (FREITAS; MAGALHÃES, 2012). Almeida e Rondon Neto (2010) identificaram, por exemplo, que a baixa riqueza de espécies presentes na arborização urbana pode ser entendida como uma falta de planejamento e de legislação para tal finalidade, ficando por conta da população a escolha das espécies, o que pode acarretar em consequências negativas no futuro dessas áreas verdes.

$\mathrm{Na}$ ausência de dados que pudessem ser utilizados para uma análise qualitativa e quantitativa da arborização urbanística do município de Lençóis Paulista, SP, buscou-se coletar informações quanto à frequência, identificação e localização de espécies, dimensionamento, fitossanidade, bem como elementos presentes no ambiente como fiação elétrica e calçadas. $O$ objetivo deste trabalho foi diagnosticar quanti e qualitativamente os indivíduos arbóreos dos bairros Jardim Ibaté, Jardim Granville e Jardim Ubirama com o intuito de realizar um comparativo entre os bairros e, nesse cenário, poder pontuar, em uma ordem crescente a qualidade dos mesmos.

\section{MATERIAL E MÉTODOS}

\section{Descrição do local}

O estudo foi realizado nos bairros Jardim Granville, Jardim Ibaté e Jardim Ubirama, município de Lençóis Paulista, localizado no centro oeste do estado de São Paulo, durante julho de 2016 e fevereiro de 2017. Lençóis Paulista apresenta uma população de 61.428 habitantes e uma área territorial de $809,541 \mathrm{~km}^{2}$ (IBGE, 2017). A cidade possui um clima tipo Aw (CEPAGRI, 2017), sendo classificado como tropical com chuvas de verão, segundo a classificação climática de Köppen Geiger. Diferentes formações vegetacionais do Cerrado e Mata Atlântica estão presentes no município, contando com dois rios em sua hidrografia, sendo eles o Rio Lençóis e o Córrego da Prata.

Os bairros estão inseridos em um zoneamento predominantemente residencial. A determinação da área de estudo foi instituída de forma aleatória, priorizando a escolha de bairros em diferentes pontos da cidade, como região central e também a periférica. $O$ bairro 
Jardim Granville possui uma área de $83,4 \mathrm{Km}^{2}$, o Jardim Ibaté conta com uma área de 96,8 $\mathrm{Km}^{2}$, e o bairro Jardim Ubirama possui área aproximada de $363,8 \mathrm{Km}^{2}$, havendo neste último, a ocorrência de comércio, principalmente próximo às avenidas arteriais da cidade.

\section{Análise do material coletado}

Para realização da coleta de dados foi utilizada uma tabela proposta por Silva Filho et al. (2002) com algumas alterações que se fizeram necessárias. Com base nas informações e no nome popular obtido no campo, as espécies identificadas foram classificadas com auxílio de material bibliográfico para posteriormente determinar a família a qual cada indivíduo pertence. Foi mensurado o perímetro na altura do peito (PAP), através da utilização de fita métrica, a altura da primeira ramificação e a altura geral do indivíduo. Este último parâmetro foi dividido em três classes sendo considerado de pequeno porte (até $5 \mathrm{~m}$ ), médio porte $(5 \mathrm{a} 10 \mathrm{~m}$ ) e grande porte (acima de $10 \mathrm{~m}$ ).

Foi registrado o equilíbrio geral de cada indivíduo, que diz respeito à apresentação do caule retilíneo e copa com proporção igual para ambos os lados, segundo Silva Filho et al. (2002). Tomaram-se como critério de inclusão árvores, arbustos e palmeiras. Analisou-se a fitossanidade, registrando-se se o indivíduo causador era cupim, lagarta ou fungo, e como era a intensidade desses ataques fitossanitários sofridos pelo indivíduo. Este parâmetro foi dividido em leve (quando havia presença de agentes, porém sem causar danos ao indivíduo), médio (presença de danos causados por agentes, no entanto, reversíveis) e pesado (danos irreversíveis que podiam ocasionar a morte do indivíduo).

Os dados coletados no campo foram organizados e processados através da utilização de planilhas e gráficos eletrônicos. A partir dos dados obtidos foi realizado um estudo comparativo entre as características presentes nos distintos bairros.

\section{RESULTADOS E DISCUSSÃO}

\section{Bairro lbaté}

Foram inventariados e identificados, no bairro Jardim lbaté, 299 indivíduos, distribuídos em 21 espécies e 16 famílias botânicas (Tabela 1). 
Tabela 1. Dados obtidos no levantamento realizado no bairro Jardim Ibaté, Lençóis Paulista - SP Table 1. Data obtained in the survey carried out in the district Jardim Ibaté, Lençóis Paulista - SP

\begin{tabular}{|c|c|c|c|c|}
\hline Espécie & Nome Comum & Família & FA & FR \\
\hline Lagerstroemia indica (L.) Pers & Resedá & Lythraceae & 79 & $26,42 \%$ \\
\hline Licania tomentosa (Benth.) Fritsch & Oiti & Chrysobalanaceae & 65 & $21,73 \%$ \\
\hline Callicarpa reevesii $\mathrm{L}$. & Calicarpa & Verbenaceae & 24 & $8,02 \%$ \\
\hline Grevillea banksii R. Br. & Grevilea-anã & Proteaceae & 18 & $6,02 \%$ \\
\hline Filicium decipens (Wight \& Arn.) Thwaites & Samambaia & Sapindaeae & 14 & $4,68 \%$ \\
\hline Murraya paniculata (L.) Jack & Dama-da-noite & Rutaceae & 14 & $4,68 \%$ \\
\hline Nerium oleander L. & Oleandro & Apocynaceae & 10 & $3,34 \%$ \\
\hline Tibouchina granulosa (Desr.) Cogn. & Quaresmeira & Melastomataceae & 10 & $3,34 \%$ \\
\hline Salix $x$ pendulina Wender. & Chorão & Salicaceae & 08 & $2,67 \%$ \\
\hline Codiaeum variegatum (L.) A.Juss. & Cróton & Euphorbiaceae & 06 & $2,00 \%$ \\
\hline Citrus limon (L.) Burm & Limão-cravo & Rutaceae & 05 & $1,67 \%$ \\
\hline Handroanthus albus (Cham.) Mattos & Ipê & Bignoniaceae & 05 & $1,67 \%$ \\
\hline Tecoma stans (L.) Jussieu ex. Kunth & Ipê-de-jardim & Bignoniaceae & 05 & $1,67 \%$ \\
\hline Duranta erecta aurea L. & Pingo-de -ouro & Verbenaceae & 03 & $1,00 \%$ \\
\hline Malpighia emarginata D.C. & Acerola & Malpighiaceae & 03 & $1,00 \%$ \\
\hline Euphorbia cotinifolia L. & Leiteiro-vermelho & Euphorbiaceae & 02 & $0,66 \%$ \\
\hline $\begin{array}{c}\text { Dypsis lutescens (H. Wendl.) } \\
\text { Beentje \& J. Dransf. }\end{array}$ & Areca-bambu & Arecaceae & 01 & $0,33 \%$ \\
\hline Rosa x grandiflora Hort. & Rosa & Rosaceae & 01 & $0,33 \%$ \\
\hline Plecthrantus barbatus Andrews & Boldo & Lamiaceae & 01 & $0,33 \%$ \\
\hline Bauhinia fortificata $L$. & Pata-de-vaca & Fabaceae & 01 & $0,33 \%$ \\
\hline \multicolumn{3}{|c|}{ Indivíduos mortos sem identificação } & 24 & $8,02 \%$ \\
\hline \multicolumn{3}{|c|}{ TOTAL } & 299 & $100 \%$ \\
\hline
\end{tabular}

$\mathrm{Na}$ classificação utilizada para estudar o estado geral dos indivíduos, observou-se que 120 indivíduos $(40,13 \%)$ foram classificados em bom estado e 15 classificados em péssimo estado, representando $5 \%$ da amostragem (Figura 1). 


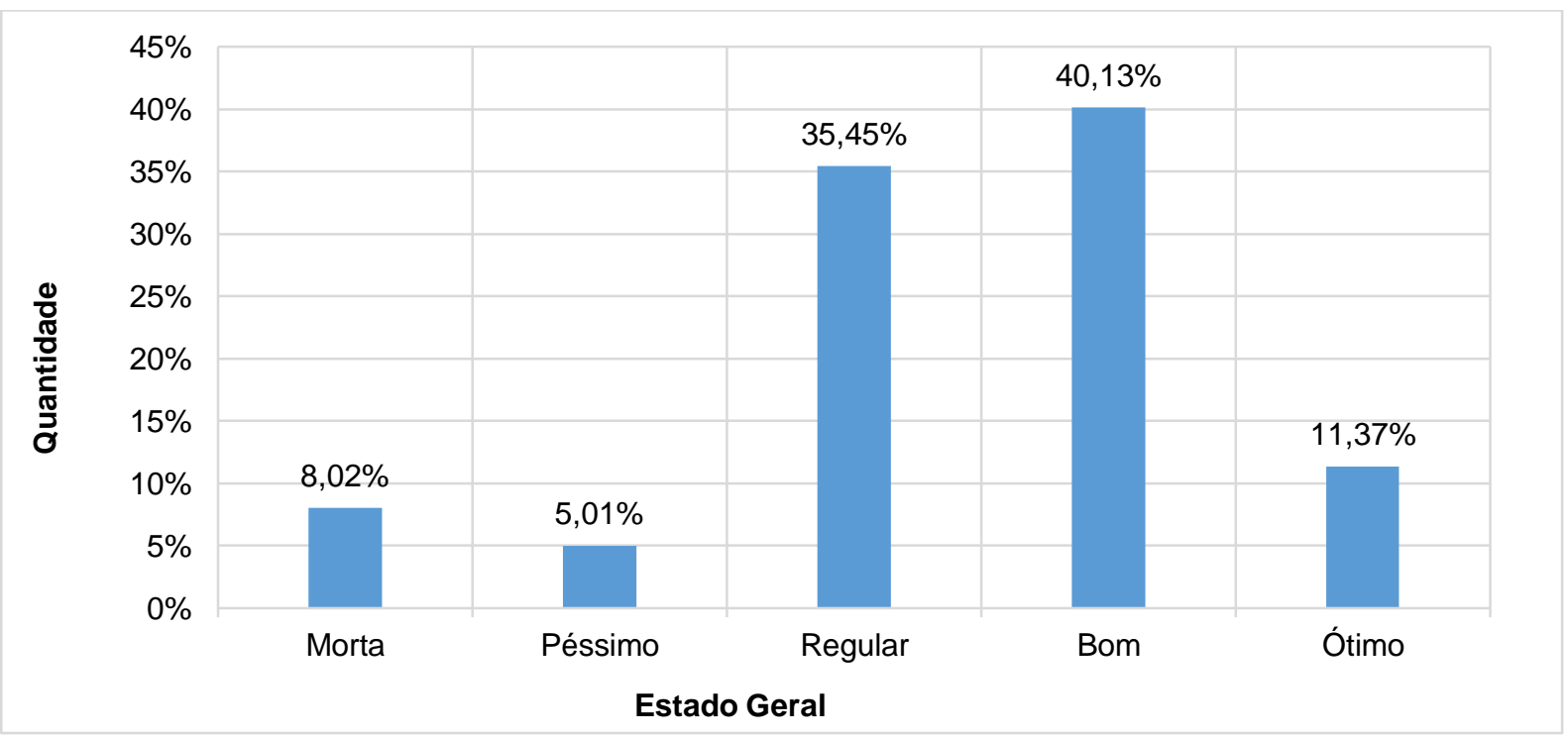

Figura 1. Quantidade de indivíduos em relação ao seu estado geral no bairro Jardim Ibaté, Lençóis Paulista - SP

Figure 1. Individuals quantity in relation to their general condition in the district Jardim Ibaté, Lençóis Paulista - SP

A altura média encontrada nas árvores foi de 3,72 metros, com uma distribuição de 201 indivíduos $(67,22 \%)$ classificados como de pequeno porte (até 5 metros), 98 indivíduos (32,77\%) como de médio porte (5 a 10 metros) e nenhum indivíduo classificado como de grande porte (acima de 10 metros).

O PAP médio foi de $12 \mathrm{~cm}$; no entanto, a menor medida foi de $2 \mathrm{~cm}$ - indicando a presença de mudas recém plantadas - e a medida máxima foi de $26 \mathrm{~cm}$. A média da altura da primeira ramificação foi de $0,40 \mathrm{~m}$.

Do total de exemplares amostrados, $86,30 \%$ não apresentaram desequilíbrio de caule ou copa; em contrapartida, $16,40 \%$ dos exemplares possuíam alguma oscilação - sendo que $23,5 \%$ apresentaram apenas desequilíbrio de copa, 55,5\% desequilíbrio de caule e em $21 \%$ dos casos foram constatados ambos os desequilíbrios.

Cerca de $65 \%$ dos indivíduos estavam isentos de qualquer tipo de infestação parasitária e 34,18\% portavam alguma infestação. Em lbitinga - SP, Gonçalves, Coral e Siqueira (2017) encontraram valores semelhantes, dos quais $68,18 \%$ dos indivíduos também portavam alguma infestação. Dentro da classificação para os ataques fitossanitários, 44,85\% dos indivíduos foram identificados como tendo sido acometidos por ataques leves, 38,18\% por ataques médios, e 16,97\% por ataques pesados. O local de ataque de maior frequência para infestação de pragas foram os ramos, sendo que $66,30 \%$ dos indivíduos apresentaram ataques nessa região.

Quanto às interferências com a infraestrutura urbana, nenhum dos indivíduos inventariados apresentou conflito com a fiação aérea, não obstante, $6 \%$ da amostragem nesse 
bairro possuía potencial para o crescimento, podendo, posteriormente, gerar algum conflito. Aproximadamente $5 \%$ já possuíam conflitos com os postes de energia, e nenhum indivíduo esteve em conflito com a iluminação pública. Constatou-se também que 4,55\% dos indivíduos obstruíam a visibilidade de placas de trânsito e que 52,30\% da amostra possuía conflitos com muros e outras construções havendo, ainda, 43,39\% de indivíduos com potencial para conflitos.

\section{Bairro Jardim Granville}

No bairro Jardim Granville foram encontrados 147 indivíduos distribuídos em 18 espécies e 14 famílias botânicas (Tabela 2).

Tabela 2. Levantamento das espécies existentes no bairro Jardim Granville, Lençóis Paulista - SP Table 2. Survey of existing species in the district Jardim Granville, Lençóis Paulista - SP

\begin{tabular}{|c|c|c|c|c|}
\hline Espécie & Nome Comum & Família & FA & FR \\
\hline Lagerstroemia indica (L.) Pers. & Resedá & Lythraceae & 27 & $18,36 \%$ \\
\hline Paubrasilia echinata Lam. & Pau-brasil & Fabaceae & 22 & $14,96 \%$ \\
\hline Salix $x$ pendulina Wender. & Chorão & Salicaceae & 13 & $8,84 \%$ \\
\hline Dypsis lutescens (H. Wendl.) Beentje \& Dransf. & Areca-bambu & Arecaceae & 13 & $8,84 \%$ \\
\hline Tibouchina granulosa (Desr.) Cogn. & Quaresmeira & Melastomataceae & 11 & $7,48 \%$ \\
\hline Liquidambar styraciflua L. & Liquidâmbar & Altingiaceae & 07 & $4,76 \%$ \\
\hline Callicarpa reevesii L. & Calicarpa & Verbenaceae & 07 & $4,76 \%$ \\
\hline Eugenia uniflora L. & Pitanga & Myrtaceae & 07 & $4,76 \%$ \\
\hline Filicium decipiens (Wight \& Arn.) Thwaites & Samambaia & Sapindaeae & 06 & $4 \%$ \\
\hline Citrus limon (L.) Burm & Limão-cravo & Rutaceae & 05 & $3,40 \%$ \\
\hline Tecoma stans (L.) Jussieu ex. Kunth & Ipê-de-jardim & Bignoniaceae & 05 & $3,40 \%$ \\
\hline Nerium oleander $\mathrm{L}$. & Oleandro & Apocynaceae & 05 & $3,40 \%$ \\
\hline Murraya paniculata (L.) Jack & Dama-da-noite & Rutaceae & 03 & $2 \%$ \\
\hline Hibiscus rosa-sinensis $\mathrm{L}$. & Hibisco & Malvaceae & 03 & $2 \%$ \\
\hline Delonix regia (Hook.) Raf. & Flamboyant & Fabaceae & 03 & $2 \%$ \\
\hline Woydetia bifurcata A. K. Irvine & Rabo-de-raposa & Arecaceae & 02 & $1,36 \%$ \\
\hline Licania tomentosa (Benth.) Fritsch & Oiti & Chrysobalanaceae & 01 & $0,68 \%$ \\
\hline Bauhinia fortificata L. & Pata-de-vaca & Fabaceae & 01 & $0,68 \%$ \\
\hline \multicolumn{3}{|c|}{ Indivíduos mortos sem identificação } & 12 & $8,16 \%$ \\
\hline \multicolumn{3}{|l|}{ TOTAL } & 147 & $100 \%$ \\
\hline
\end{tabular}


$\mathrm{Na}$ avaliação que classificou o estado geral dos indivíduos, foram identificados 31 em ótimo estado (21\%), 58 em bom estado (39,45\%), 40 classificados como regular $(27,21 \%), 6$ em péssimo estado e 12 mortos, representando 4\% e 8\%, respectivamente (Figura 2).

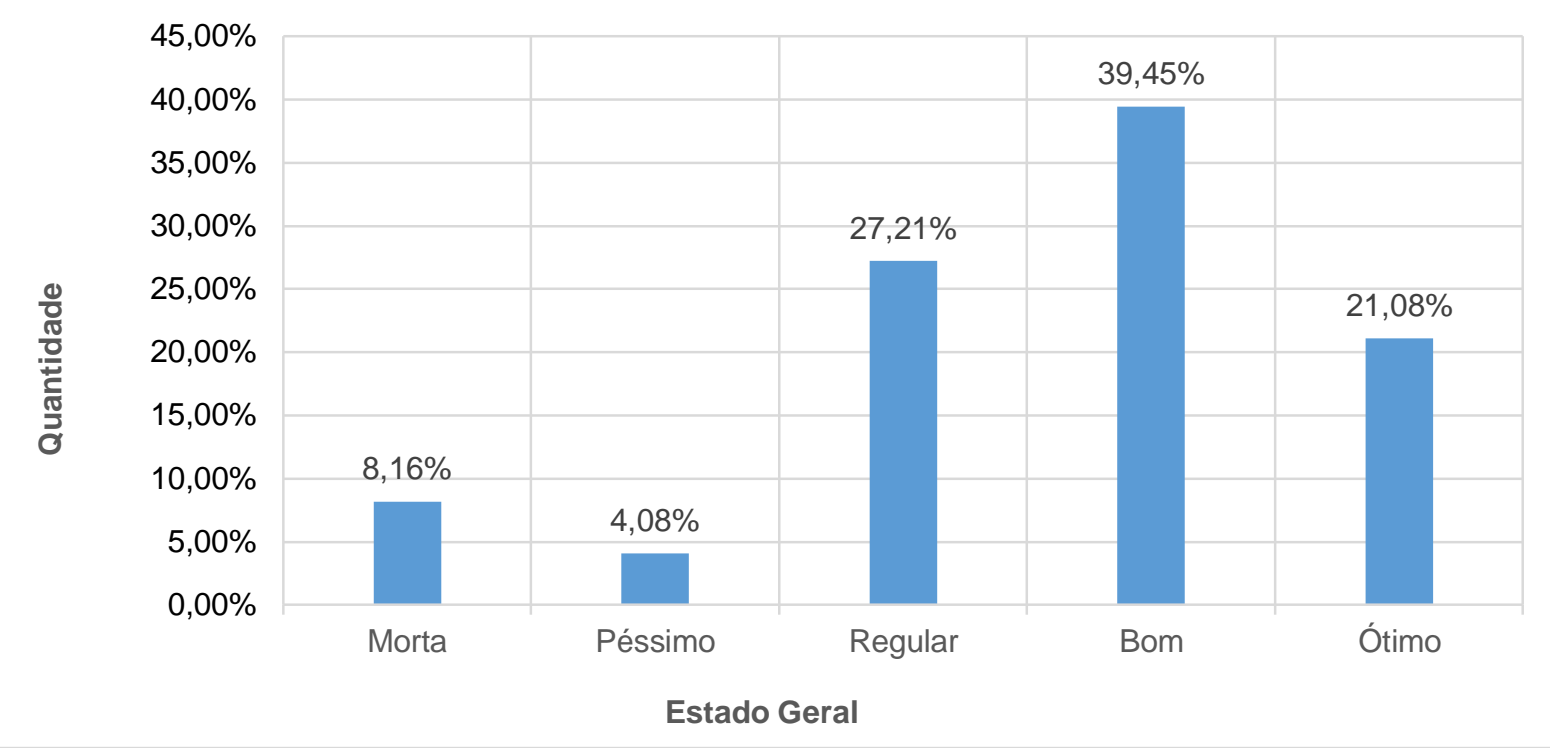

Figura 2. Quantidade de indivíduos em relação ao seu estado geral no bairro Jardim Granville, Lençóis Paulista - SP

Figure 2. Individual quantity number in relation to their general condition in the district Jardim Granville, Lençóis Paulista - SP

A altura média encontrada foi de $6,34 \mathrm{~m}$, com uma distribuição de 55 indivíduos (37,41\%) classificados como de pequeno porte, 68 indivíduos $(46,25 \%)$ como de médio porte e 24 indivíduos (16,32\%) classificados como de grande porte.

O PAP médio foi de $52 \mathrm{~cm}$, indicando uma quantidade elevada de espécies adultas em relação ao bairro Jardim lbaté. A menor medida foi de $7 \mathrm{~cm}$ - e a medida máxima foi de 150 $\mathrm{cm}$. A média da altura da primeira ramificação foi de $0,83 \mathrm{~m}$.

Nesse bairro, a ocorrência de desequilíbrio no caule e na copa das árvores ocorreu em $37,12 \%$ dos indivíduos apresentaram desequilíbrio, dos quais, 48,13\% ocorrendo na copa e $20,77 \%$ no caule. Indivíduos com ambos os desequilíbrios atingiram $31,10 \%$.

As infestações parasitárias neste bairro se encontraram ausentes em $70,65 \%$ dos indivíduos analisados. Daqueles que se registrou infestação, os ataques leves foram de $29,67 \%$, ataques médios em $70,33 \%$ e ataques pesados em $10 \%$.

Quanto às interferências com a infraestrutura urbana no bairro jardim Granville, $39,40 \%$ dos indivíduos inventariados apresentaram conflito com a fiação aérea, não obstante, $17,22 \%$ da amostragem possuía potencial para o crescimento, podendo, posteriormente, gerar algum conflito. Aproximadamente $4,5 \%$ já possuíam conflitos com os postes de energia, e $1,36 \%$ da amostragem apresentou conflito com a iluminação pública. Constatou-se também 
que $0,46 \%$ dos indivíduos obstruíam a visibilidade de placas de trânsito e que $80,78 \%$ da amostra possuía conflitos com muros e outras construções, havendo ainda, $10,39 \%$ de indivíduos com potencial para outros tipos de conflitos.

\section{Bairro Jardim Ubirama}

No bairro Jardim Ubirama, 693 indivíduos foram identificados, distribuídos em 26 espécies e 17 famílias botânicas (Tabela 3).

Tabela 3. Levantamento das espécies existentes no bairro Jardim Ubirama, Lençóis Paulista - SP Table 3. Survey of existing species in the district Jardim Ubirama, Lençóis Paulista - SP

\begin{tabular}{|c|c|c|c|c|}
\hline Espécie & Nome Comum & Família & FA & FR \\
\hline Murraya paniculata (L.) Jack & Dama-da-noite & Rutaceae & 163 & $23,52 \%$ \\
\hline Woydetia bifurcata A.K.Irvin & Rabo-de-raposa & Arecaceae & 50 & $7,21 \%$ \\
\hline $\begin{array}{c}\text { Dypsis lutescens } \\
\text { (H. Wendl.) Beentje \& Dransf. }\end{array}$ & Areca-bambu & Arecaceae & 44 & $6,34 \%$ \\
\hline Lagerstroemia indica (L.) Pers. & Resedá & Lythraceae & 43 & $6,20 \%$ \\
\hline Nerium oleander L. & Oleandro & Apocynaceae & 35 & $5,05 \%$ \\
\hline Licania tomentosa (Benth.) Fritsch & Oiti & Chrysobalanaceae & 30 & $4,32 \%$ \\
\hline Eugenia uniflora L. & Pitanga & Myrtaceae & 26 & $3,75 \%$ \\
\hline Tibouchina granulosa (Desr.) Cogn. & Quaresmeira & Melastomataceae & 22 & $3,17 \%$ \\
\hline Malpighia emarginata DC. & Acerola & Malpighiaceae & 22 & $3,17 \%$ \\
\hline Handroanthus albus (Cham.) Mattos & Ipê-amarelo & Bignoniaceae & 16 & $2,30 \%$ \\
\hline Salix $x$ pendulina Wender. & Chorão & Salicaceae & 15 & $2,16 \%$ \\
\hline Pterocarpus violaceus Vog. & Aldrago & Fabaceae & 15 & $2,16 \%$ \\
\hline Callicarpa reevesii L. & Calicarpa & Verbenaceae & 15 & $2,16 \%$ \\
\hline $\begin{array}{c}\text { Paubrasilia echinata } \\
\text { DC. var. peltophoroides (Benth.) G. P. Lewis }\end{array}$ & Sibipiruna & Fabaceae & 13 & $1,87 \%$ \\
\hline Filicium decipiens (Wight \& Arn.) Thwaites & Samambaia & Sapindaeae & 11 & $1,58 \%$ \\
\hline Tecoma stans (L.) Jussieu ex. Kunth & Ipê-de-jardim & Bignoniaceae & 10 & $1,44 \%$ \\
\hline Bauhinia fortificata $\mathrm{L}$. & Pata-de-vaca & Fabaceae & 10 & $1,44 \%$ \\
\hline Duranta erecta aurea L. & Pingo-de-ouro & Verbenaceae & 9 & $1,29 \%$ \\
\hline $\begin{array}{c}\text { Paubrasilia echinata (Lam.) E. Gagnon, H.C. } \\
\text { Lima \& G.P. Lewis }\end{array}$ & Pau-brasil & Fabaceae & 9 & $1,29 \%$ \\
\hline Citrus limon (L.) Burm & Limão-cravo & Rutaceae & 9 & $1,29 \%$ \\
\hline Pterocarpus violaceus Vahl. & Aldrago & Fabaceae & 8 & $1,15 \%$ \\
\hline Nectandra megapotamica (Spreng.) Mez & Canelinha & Lauraceae & 8 & $1,15 \%$ \\
\hline Rosa x grandiflora Hort. & Rosa & Rosaceae & 3 & $0,43 \%$ \\
\hline Cassia fistula L. & Chuva-de-ouro & Fabaceae & 3 & $0,43 \%$ \\
\hline Hibiscus rosa-sinensis L. & Hibisco & Malvaceae & 3 & $0,43 \%$ \\
\hline Plecthrantus barbatus Andrews. & Boldo & Lamiaceae & 3 & $0,43 \%$ \\
\hline \multicolumn{3}{|c|}{ Indivíduos mortos sem identificação } & 98 & $14,14 \%$ \\
\hline \multicolumn{3}{|c|}{ TOTAL } & 693 & $100 \%$ \\
\hline
\end{tabular}

Quanto à avaliação que classifica o estado geral dos indivíduos, foram identificados 60 indivíduos em ótimo estado, representando 8,65\% do total; 228 indivíduos classificados em bom estado representando 32,90\%; 205 indivíduos classificados em estado regular (29,58\%), 
102 classificados em péssimo estado (14,71\%) e 98 como sendo mortos (14,14\%) (Figura 3). A causa de algumas dessas mortes neste bairro decorre de podas exageradas que por sua vez acabem desequilibrando o ecossistema da árvore, o que exige à substituição em alguns casos do indivíduo por completo. Através de um bom planejamento e manejo, esse tipo de ação poderia ser evitado, visto ser considerada uma atividade que demanda recursos humanos e despesas para o poder público, segundo Oliveira et al. (2015).

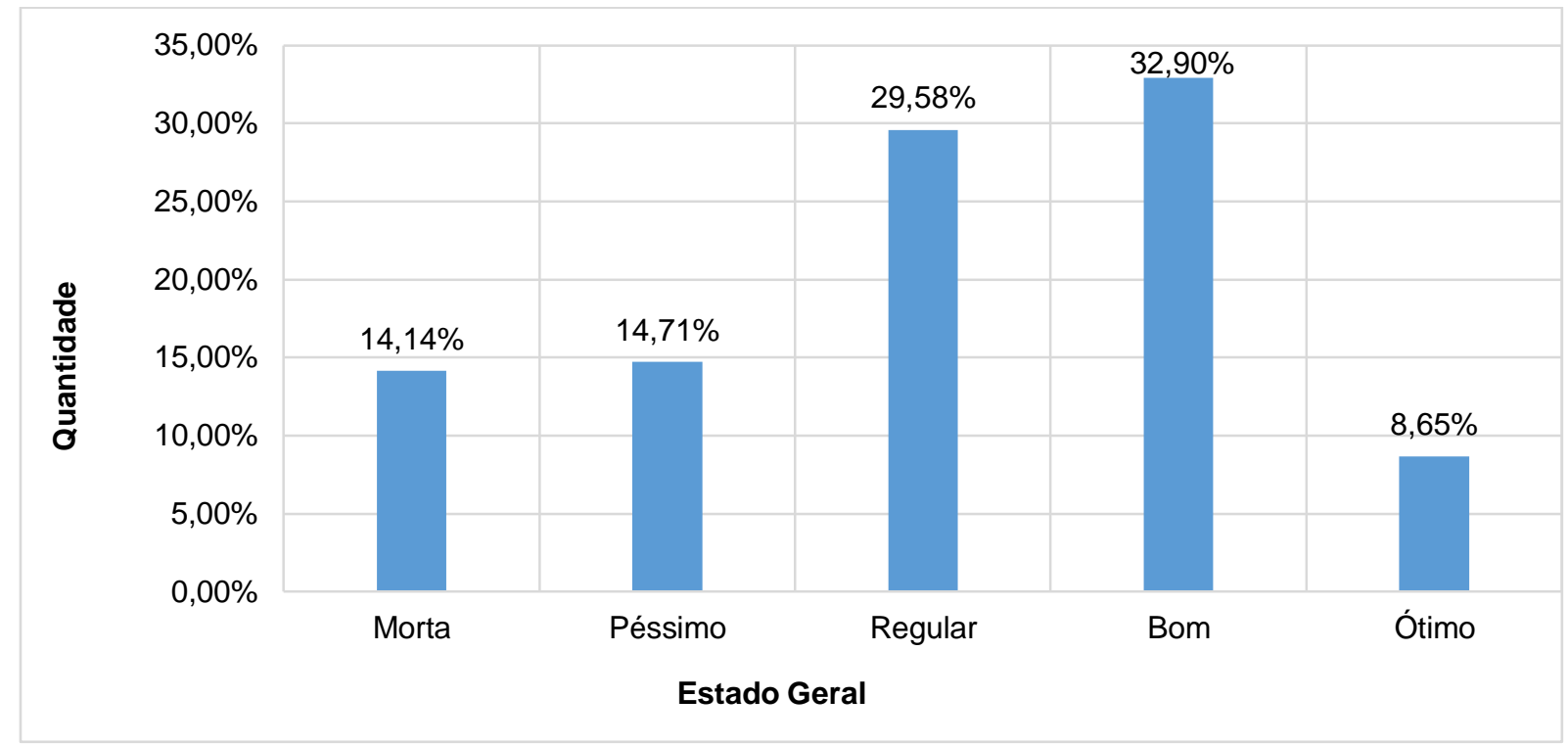

Figura 3. Quantidade de indivíduos em relação ao seu estado geral no bairro Jardim Ubirama, Lençóis Paulista - SP

Figure 3. Individuals quantity in relation to their general condition in the district Jardim Ubirama, Lençóis Paulista - SP

A altura média encontrada para as árvores foi de 7,53 metros, com uma distribuição de 221 indivíduos $(31,89 \%)$ classificados como de pequeno porte, 242 indivíduos (34,92\%) como de médio porte e 230 indivíduos $(33,18 \%)$ classificados como de grande porte.

O PAP médio foi de $40 \mathrm{~cm}$. A menor medida foi de $9 \mathrm{~cm}$ e a medida máxima foi de 150 $\mathrm{cm}$. A média da altura da primeira ramificação foi de $1 \mathrm{~m}$. Nesse bairro, a ocorrência de desequilíbrio no caule e na copa das árvores foi maior. 53,54\% dos indivíduos apresentaram desequilíbrio, dos quais, $60,89 \%$ ocorrendo na copa e $26,11 \%$ no caule. Indivíduos com ambos os desequilíbrios atingiram 13\%. Esses valores foram ultrapassados em relação, por exemplo, a Aracaju - SE, em que Santos et al. (2015) diagnosticaram que 42\% dos indivíduos inventariados também apresentavam má relação do caule e da copa.

As infestações parasitárias neste bairro se encontraram presentes em $62,30 \%$ dos indivíduos analisados. É um problema que acontece na arborização urbana de forma geral e que pode ser resolvido, segundo Macedo, Lisboa e Carvalho (2012) quando se é feita a substituição gradativa das atuais árvores infectadas por outras espécies que possuam 
características morfológicas adequadas às situações dos centros urbanos. Dos indivíduos que se registrou infestação, os ataques leves foram de 14,75\%, ataques médios em 60,87\% e ataques pesados em $24,38 \%$. Esta situação pode acontecer em árvores que estão situadas no âmbito urbanizado, pois, de acordo com Araújo et al. (2012), as árvores urbanas estão mais expostas para ataque de pragas e doenças, por conta do ambiente antrópico. Não obstante, a melhor seleção de espécies e suas respectivas quantidades na arborização proporcionarão menores índices de infestações (MACEDO; LISBOA; CARVALHO, 2012).

Quanto às interferências com a infraestrutura urbana deste bairro, 40,94\% dos indivíduos inventariados apresentaram conflito com a fiação aérea, não obstante, 10,30\% da amostragem apresentaram potencial para o crescimento, podendo, posteriormente, gerar algum conflito. Aproximadamente $10 \%$ já apresentavam conflitos com os postes de energia, e 0,93\% da amostragem apresentou conflito com a iluminação pública. Constatou-se também que $0,68 \%$ dos indivíduos obstruíam a visibilidade de placas de trânsito e que $65,40 \%$ dos indivíduos possuíam conflitos com muros e outras construções, havendo ainda, 7,48\% de indivíduos com potencial para outros eventuais conflitos.

A variedade de espécies catalogadas nos bairros mostrou-se baixa em relação a outros municípios das regiões sul e sudeste do país. Em Porto Alegre (RS), foram identificadas 61 espécies (SALVI et al., 2011), em Lages (RS) obteve-se a catalogação de 50 espécies (BASTOS et al., 2016), e em São Paulo (SP), 42 espécies (ROSSETTI; PELLEGRINO; TAVARES, 2010). Não obstante, análises realizadas em um bairro de Uberlândia - MG (REZENDE; SANTOS, 2010), trouxeram uma riqueza de espécies semelhantes às que constam nos bairros deste estudo. Em Ibitinga, por exemplo, o número de espécies também se encontrava baixo, com 22 espécies amostradas (GONÇALVES; CORAL; SIQUEIRA, 2017), bem como em Arapiraca (AL), onde foram encontradas 9 espécies (SILVA, 2012). Para um programa ideal de arborização é necessário que haja grande diversidade de espécies, tendo em vista maior proteção e controle de pragas e doenças. É recomendado que uma determinada espécie não ultrapasse o valor de $10 \%$ da população total (SANTAMOUR JÚNIOR, 1990). No bairro Jardim Ibaté as espécies Lagerstroemia indica e Licania tomentosa atingiram $26,42 \%$ e $21,73 \%$ do total, respectivamente, ultrapassando o valor recomendado. A mesma situação se repetiu no bairro Jardim Granville em uma condição menos tênue, onde as espécies Paubrasilia echinata e Salix x pendulina chegaram a 18,36\% e 14,96\%, respectivamente. Já no bairro Jardim Ubirama a porcentagem de Murraya paniculata chegou a $23,52 \%$, sendo o único bairro com apenas um espécie acima dos $10 \%$.

Dentre os 1.139 indivíduos amostrados nos três bairros avaliados, apenas 10,97\% apresentavam ótimo estado e 34,94\% apresentaram bom estado, totalizando $45,91 \%$ dos indivíduos em condições ideais para compor a arborização urbana. Já os indivíduos que 
apresentavam estado geral tido como regular representaram $30,81 \%$, os que foram classificados como em péssimo estado, $10,79 \%$ e os mortos, $11,76 \%$. Nesse contexto, é importante reforçar a necessidade de manejo com profissionais qualificados, a fim de atenuar os aspectos negativos nos indivíduos, melhorando a qualidade de vida tanto da arborização, quanto dos habitantes (MACEDO; LISBOA; CARVALHO, 2012). A título de comparação, podese citar Moura e Santos (2009), que encontraram em Várzea Grande - MT, 82\% dos indivíduos em boas condições, $16 \%$ registrados como regular e $2 \%$ ruins, indicando ainda assim a necessidade de melhorar o plano de manejo para as árvores já existentes nessa localidade.

\section{CONCLUSÕES}

Constatou-se que a arborização urbana nos três bairros avaliados apresentaram exígua distribuição de espécies e alta frequência de algumas espécies, como a Murraya paniculata ocorrendo no bairro Jardim Ubirama; Lagerstroemia indica e Paubrasilia echinata no bairro Jardim Granville; Licania tomentosa e novamente Lagerstroemia indica, no bairro Jardim Ibaté. A ocorrência de indivíduos em péssimo estado ou mortos apresentou valores mais significativos no bairro Jardim Ubirama. Não obstante, indivíduos que apresentaram estado geral considerados ótimo/bom foram mais ocorrentes no bairro Jardim Granville. A falta de manutenção foi observada pelo conflito dos indivíduos com a fiação aérea e muros das edificações, sendo mais evidente no bairro Jardim Granville. Constatou-se também que o bairro Ubirama apresentou, entre os demais, os maiores problemas fitossanitários, com $62,30 \%$ dos indivíduos infectados. O estudo aponta que a arborização urbana analisada nos bairros ocorre de forma desigual, considerando o bairro Jardim Granville melhor arborizado, seguidamente do bairro Jardim Ibaté, e necessitando de intensas intervenções o bairro Jardim Ubirama.

\section{AGRADECIMENTOS}

Agradecemos aos revisores pelas relevantes contribuições ao manuscrito. 


\section{REFERÊNCIAS}

ALMEIDA, D. N.; RONDON NETO, R. M. Análise da arborização urbana de duas cidades da região norte do estado de Mato Grosso. Revista Árvore, Viçosa, v. 34, n. 5, p. 899-906, 2010.

ARAÚJO, A. C. B.; GRACIOLI, C. R.; GRIMM, E. L.; LONGHI, S. J. Avaliação da florística, do porte e da fitossanidade atual da arborização do Parque Internacional de Sant'ana do Livramento/Rivera, Brasil/Uruguay. Revista da Sociedade Brasileira de Arborização Urbana, Piracicaba, v. 7, n. 1, p. 112-125, 2012.

BAstos, F. E. A.; CAMARGO, S. S.; MENEGuZZI, A.; KRETZSCHMAR, A.; RUFATO, L. Levantamento florístico e características das espécies em praças públicas em Lages - SC. Revista da Sociedade Brasileira de Arborização Urbana, Piracicaba, v. 11, n. 6, p. 34-42, 2016.

BERTINI, M. A.; RUFINO, R. R.; FUSHITA, A. T.; LIMA, M. I. S. Public green areas and urban environmental quality of the city of São Carlos, São Paulo, Brazil. Brazilian Journal of Biology, São Carlos, v. 76, n. 3, p. 700-707, 2016.

BOBROWSKI, R. Inventário florestal contínuo e dinâmica da arborização de ruas. In: BIONDI, D.; LIMA NETO, E. M. (Org.). Pesquisa em arborização de ruas. Curitiba: O Autor, 2011. p. 109-130.

CENTRO DE PESQUisAs METEREOLOGICAS E CLIMÁtICAS APLICADAS A AGRICULTURA (CEPAGRI). Clima dos municípios paulistas. Disponível em: <http://www.cpa.unicamp.br/outras-informacoes/clima_muni_305.html>. Acesso em: 16 ago. 2017.

FREITAS, W. K.; MAGALHÃES, L. M. S. Métodos e Parâmetros para Estudo da Vegetação com Ênfase no Estrato Arbóreo. Floresta e Ambiente, Rio de Janeiro, v. 19, n. 4, p. 520-540, 2012.

GONÇALVES, W. B.; CORAL, D. J.; SIQUEIRA, M. V. B. M.; Caracterização da arborização urbana no bairro centro do município de Ibitinga/SP. Revista Sociedade Brasileira de Arborização Urbana, Piracicaba, v. 12, n. 3, p. 66-79, 2017.

INSTITUTO BRASILEIRO DE GEOGRAFIA E ESTATÍSTICA - IBGE. Disponível em: <http://www.cidades.ibge.gov.br/xtras/home.php>. Acesso em: 21 set. 2015.

MACEDO, B. R. M. de; LISBOA, C. M. C. A.; CARVALHO, F. G. Diagnóstico e diretrizes para a arborização do campus central da Universidade Federal do Rio Grande do Norte. Revista da Sociedade Brasileira de Arborização Urbana, Piracicaba, v. 7, n. 1, p. 35-51, 2012.

MASCARÓ, L; MASCARÓ, J. Vegetação Urbana. 2. ed. Porto Alegre: +4 Editora, 2005.

MORAES, A. F.; GOUDARD, B.; OLIVEIRA, R. Reflexões sobre a cidade, seus equipamentos urbanos e a influência destes na qualidade de vida da população. Revista Internacional Interdisciplinar INTERthesis, Florianópolis, v. 5, n. 2, p. 93-103, 2008.

MOURA, T. A.; SANTOS, V. L. L. V. Levantamento quali-quantitativo de espécies arbóreas e arbustivas na arborização viária urbana dos bairros centro e centro norte, Várzea Grande, Mato 
Grosso, Brasil. Revista da Sociedade Brasileira de Arborização Urbana, Piracicaba, v. 1, n.1, p. 97-117, 2009.

OliveirA, A. F.; PeReirA, J. A. A.; PeReIRA, G. A.; COElHO, S. J.; NeVES, C. L. P.; REZENDE, S. W. GARCIA, F. H. S. Modalidades de poda avaliadas na arborização viária sob rede elétrica no estado de Minas Gerais. Revista da Sociedade Brasileira de Arborização Urbana, Piracicaba, v.10, n.2, p. 1-13, 2015.

REZENDE, T. M.; SANTOS, D. G. Avaliação quali-quantitativa da arborização das praças do bairro Jaraguá, Uberlândia - MG. Revista da Sociedade Brasileira de Arborização Urbana, Piracicaba, v. 5, n. 2, p. 139-157, 2010.

ROSSETTI, A. I. N.; PELLEGRINO, P. R. M.; TAVARES, A. R. As árvores e suas interfaces no ambiente urbano. Revista da Sociedade Brasileira de Arborização Urbana, Piracicaba, v. 5, n. 1, p. 1-24, 2010.

SALVI, L. T.; HARDT, L. P. A.; ROVEDDER, C. E.; FONTANA, C. S. Arborização ao longo de ruas - túneis verdes - em Porto Alegre, RS, Brasil: avaliação quantitativa e qualitativa. Revista Árvore, Viçosa, v. 35, n. 2, 2011.

SANTAMOUR JÚNIOR, F.S. Trees for urban planting: diversity uniformity, and common sense. In: METRIA Conference, 7., 1990, Lisle. Proceedings... Lisle: 1990. p.57-66.

SANTOS, C. Z. A.; FERREIRA, R. A.; SANTOS. L. R.; SANTOS, L. I.; GOMES, S. H.; GRAÇA, D. A. S. Análise qualitativa da arborização urbana de 25 vias públicas da cidade de Aracaju SE. Revista Ciência Florestal, Santa Maria, v. 25, n. 3, p. 751-763, 2015.

SANTOS, T. O. B.; LISBOA, C. M. C. A.; CARVALHO, F. G. Análise da arborização viária do bairro de Petrópolis, Natal, RN: uma abordagem para diagnóstico e planejamento da flora urbana. Revista da Sociedade Brasileira de Arborização Urbana, Piracicaba, v. 7, n. 4, p. 90-106, 2012.

SHAMS, J. C. A.; GIACOMELI, D. C.; SUCOMINE, N. M. Emprego da arborização na melhoria do conforto térmico nos espaços livres públicos. Revista da Sociedade Brasileira de Arborização Urbana, Piracicaba, v. 4, n. 4, p. 1-16, 2009.

SILVA, I. M. da; GONZALEZ, L. R.; SILVA FILHO, D. F. da. Recursos naturais de conforto térmico: um enfoque urbano. Revista da Sociedade Brasileira de Arborização Urbana, Piracicaba, v. 6, n. 4, p. 35 - 50, 2011.

SILVA JÚNIOR, O. A. B.; MÔNICO, M. O. M. Arborização em Harmonia com a Infraestrutura Urbana. In: 1ㄹ Semana de Meio Ambiente. Prefeitura Municipal de Guarulhos: Secretaria de Meio Ambiente, 1994.

SILVA FILHO, D. F. da; PIZETTA, P. U. C.; ALMEIDA, J. B. S. A. de; PIVETTA, K. F. L.; FERRAUDO, A. S. Banco de dados relacional para cadastro, avaliação e manejo da arborização em vias públicas. Revista Árvore, Viçosa, v. 26, n. 5, p. 629-642, 2002.

SILVA, R. N. Caracterização e análise quali-quantitativa da arborização em praças da área central da cidade de Arapiraca, AL. Revista da Sociedade Brasileira de Arborização Urbana, Piracicaba, v. 7, n. 2, p. 102-115, 2012. 